\title{
Home physiotherapy with vs. without supervision of physiotherapist for assessing manipulation under anaesthesia after total knee arthroplasty
}

Sanjay Bhalchandra Londhe ${ }^{1 *}$ D , Ravi Vinod Shah², Amit Pankaj Doshi ${ }^{3}$, Shubhankar Sanjay Londhe ${ }^{4}$, Kavita Subhedar ${ }^{5}$, Krishnan Iyengar ${ }^{6}$ and Prashant Mukkannavar ${ }^{7}$

Abstract: The aim of this retrospective cohort study was to compare home physiotherapy with or without supervision of physiotherapist for assessing manipulation under anaesthesia after total knee arthroplasty.

Methods: A total of 900 patients (including 810 females and 90 males) who had undergone total knee arthroplasty were divided into group A $(n=300)$ and group B $(n=600)$. Patients in group A had home physiotherapy on their own after discharge from hospital. The physiotherapist did not visit them at home. Patients in group $B$ received home physiotherapy under supervision of physiotherapist for 6 weeks after discharge from hospital. Patients' age, range of motion of the knee, and forgotten joint score-12 were assessed. A $p<0.05$ was considered statistically significant.

Results: In group A, the mean age was $69.1 \pm 14.3$ years (range: 58 to 82 years); in group $B$, the mean age was $66.5 \pm 15.7$ years (range: 56 to 83 years) $(p>0.05$ ). Preoperatively, the mean range of motion of the knee in group $A$ and $B$ was $95.8^{\circ} \pm 18.1^{\circ}$ and $95.4^{\circ} \pm 17.8^{\circ}$, respectively $(p>0.05)$. The mean forgotten joint score- 12 of group $A$ and $B$ were $11.90 \pm 11.3$ and $11.72 \pm 12.1(p>0.05)$, respectively. Six weeks after total knee arthroplasty, the mean ROM of the knee in group $A$ and $B$ was $109.7^{\circ} \pm 22.3^{\circ}$ and $121^{\circ} \pm 21.5^{\circ}$, respectively $(p<0.05)$. The mean postoperative forgotten joint score-12 of the group $A$ and $B$ was $24.5 \pm 16.4$ and $25.6 \pm 17.4$, respectively $(p>0.05)$. The rate of manipulation under anaesthesia was $3 \%$ in group $A$ and $0.2 \%$ in group $B(p<0.05)$.

Conclusion: After total knee arthroplasty, frequent physiotherapist's instruction helps the patients improve knee exercises and therefore decrease the risk of revision surgery. The home physiotherapy under supervision of physiotherapist lowers the rate of manipulation under anaesthesia.

Level of evidence: Therapeutic study, Level lla.

Keywords: Total knee arthroplasty, Manipulation under anaesthesia, Postoperative physiotherapy, Stiff knee

\footnotetext{
* Correspondence: sanlondhe@yahoo.com

'Orthopaedic surgeon, Criticare Hospital, Plot No 516, Besides SBI, Teli Gali, Andheri East, Mumbai, Maharashtra 400069, India

Full list of author information is available at the end of the article
}

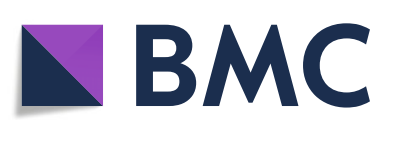

(C) The Author(s). 2021 Open Access This article is licensed under a Creative Commons Attribution 4.0 International License, which permits use, sharing, adaptation, distribution and reproduction in any medium or format, as long as you give appropriate credit to the original author(s) and the source, provide a link to the Creative Commons licence, and indicate if changes were made. The images or other third party material in this article are included in the article's Creative Commons licence, unless indicated otherwise in a credit line to the material. If material is not included in the article's Creative Commons licence and your intended use is not permitted by statutory regulation or exceeds the permitted use, you will need to obtain permission directly from the copyright holder. To view a copy of this licence, visit http://creativecommons.org/licenses/by/4.0/. 


\section{Introduction}

Total Knee Arthroplasty (TKA) is one of the most successful operations in modern orthopaedics [1]. TKA is highly effective in relieving pain and improving functions, including activities of daily living [2-6]. Huge advances have been made in the implant designs, refinement of the surgical treatment of TKA and patient selection. Bourne et al. [7] and other authors showed that a sizable percentage of patients, i.e., 19\%. remain dissatisfied with their primary TKA [8-13]. One of the common reasons in these 19\% unsatisfied patients is development of knee stiffness after the TKA surgery. If untreated, knee stiffness may progress over time and affects patients' ability to perform daily tasks [14]. Early gait analyses and biomechanical studies showed that the knee should achieve at least $83^{\circ}$ of flexion to ascend stairs, $90^{\circ}$ to $100^{\circ}$ of flexion to descend stairs, $93^{\circ}$ to $105^{\circ}$ flexion to rise from a chair, and more than $120^{\circ}$ of flexion to squat or kneel [15-17]. Till now, there is no clear consensus on the definition of knee stiffness in the literature. Usually, a stiff knee is confirmed when the knee flexed less than $90^{\circ}$ after TKA [18-20]. Some factors may be associated with knee stiffness, including a decreased preoperative ROM, younger age, diabetes mellitus, socioeconomic status, and previous knee surgery, malpositioning of implant, inadequate resection, and overstuffing of the component [21-24].

The objective of this retrospective cohort study was to compare home physiotherapy with and without supervision of physiotherapist for assessing MUA after TKA. We also reported the efficacy of postoperative home physiotherapy under supervision of physiotherapist.

\section{Patients and methods}

The institutional review boards of the participating hospitals approved the study. Informed consent was obtained from each patient.

A total of 900 patients (involving 810 females and 90 males) were included in this study and divided into two groups. Group A consisted of 300 patients who had undergone TKA between January 2011 and December 2013; group B included 600 patients who had undergone TKA between January 2014 and December 2018

Preoperatively, we recorded patients' age, body mass index (BMI), ROM of the knee, diagnosis, degree of varus deformity, 100-mm visual analogue score (VAS) for knee pain, and forgotten joint score (FJS)-12 (Table 1). The duration of hospital stay, and hipknee-ankle alignment were also recorded (Table 2). An independent observer who did not attend the treatments assessed all the data. MUA was carried out when the knee flexion was less than $90^{\circ}$ at the end of the sixth postoperative week. The study was started with null hypothesis. Using a pocket goniometer, ROM (angle of maximal flexion to extension) of the knee was measured by an independent observer (nurse practitioner). Preoperative data were recorded 1 week prior to TKA.

\section{TKA and physiotherapy}

All operations were done by the same surgical team. Operation was performed under tourniquet control and through the standard parapatellar approach. We used a cemented posterior stabilized knee implant (Freedom Total Knee system, Maxx Orthopedics Inc., PA, USA) in all patients. The physiotherapy was started immediately after TKA, i.e., on the very same day of the operation. The physiotherapy was in the form of muscle strengthening exercises, ROM exercises, closed chain exercises, and practice of stair climbing and gait training. The muscle strengthening exercises were in the form of ankle pump, static and dynamic quadriceps muscle strengthening, and glutei and hamstring muscle strengthening exercises. The ROM exercises comprised of passive, assisted active and active knee movements. Gait training included walking initially with walking aid like walker and gradually progressing to walking stick.

Patients of group A were instructed to have physiotherapy on their own at home. The physiotherapist did not visit them at home. The physiotherapist just gave them instructions at the time of discharge from the hospital. We provided information booklets to show how the physiotherapy exercises were performed.

Patients of group B received postoperative physiotherapy at home with physiotherapist visiting their home for 6 weeks. The physiotherapist visited the patients at home initially 6 days a week (excluding Sunday) for the first 2 weeks, 3 days a week for the next 2 weeks, and then once a week for the final 2 weeks. The same physiotherapy team conducted the home physiotherapy. The information conveyed by the physiotherapist included ROM, walking with/without walking aid, ability to perform day to day activities, and amount of knee pain the patient was experiencing.

MUA was applied when the patients had failed to achieve $90^{\circ}$ of ROM at the first follow-up visit ( 6 weeks after TKA). Under general anaesthesia, the patient underwent MUA as a day care procedure and was put on standard post-TKA rehabilitation program. Postoperative data were recorded at each clinic visit.

\section{Statistical analysis}

Data were expressed as mean \pm standard deviation. Comparisons between the groups were made by using 
Table 1 Comparison of preoperative characteristics of patients between Group A and Group B

\begin{tabular}{|c|c|c|c|}
\hline Parameters & Group A & Group B & $p$ value \\
\hline Number of patients $(n)$ & 300 & 600 & - \\
\hline Mean Age (years) & $69.1 \pm 14.3(58-82)$ & $66.5 \pm 15.7(56-83)$ & 0.5780 \\
\hline Mean BMI $\left(\mathrm{kg} / \mathrm{m}^{2}\right)$ & $28.2 \pm 4.7$ & $27.6 \pm 5.4$ & 0.1016 \\
\hline \multicolumn{4}{|l|}{ Gender } \\
\hline Females & $n=269(89.66 \%)$ & $n=542(90.33 \%)$ & 0.7511 \\
\hline Males & $n=31(10.33 \%)$ & $n=58(9.66 \%)$ & 0.7510 \\
\hline Mean Preoperative ROM & $95.8 \pm 18.1$ & $95.4 \pm 17.8$ & 0.7521 \\
\hline Preoperative degree of deformity (varus) & $8.5 \pm 2.6$ & $9.8 \pm 3.1$ & 0.1498 \\
\hline \multicolumn{4}{|l|}{ Preoperative clinical diagnosis } \\
\hline $\mathrm{OA}$ & $n=268(89.33 \%)$ & $n=533(88.83 \%)$ & 0.8213 \\
\hline RA & $n=30(10 \%)$ & $n=62(10.33 \%)$ & 0.8776 \\
\hline Others & $n=2(0.67 \%)$ & $n=5(0.83 \%)$ & 0.7967 \\
\hline \multicolumn{4}{|l|}{ Preoperative Associated co-morbidities: } \\
\hline Cardiac & $112(37.33)$ & $230(38.33)$ & 0.7709 \\
\hline Renal & $53(17.66)$ & $137(22.833)$ & 0.0732 \\
\hline Hepatic & $10(3.33)$ & $16(2.833)$ & 0.6594 \\
\hline Mean Preoperative FJS-12 & $11.90 \pm 11.3$ & $11.72 \pm 12.1$ & 0.8298 \\
\hline Mean Preoperative VAS score & $7.4 \pm 2.9$ & $7.5 \pm 1.5$ & 0.3899 \\
\hline
\end{tabular}

Student's unpaired $t$-test. The null hypothesis was tested with chi-squared test and $t$-test. A $p<0.05$ was considered statistically significant.

\section{Results}

The results were expressed as the mean \pm standard deviation. In group $\mathrm{A}$, the mean age was $69.1 \pm 14.3$ years (range: 58 to 82 years). In group $B$, the mean age was $66.5 \pm 15.7$ years (range: 56 to 83 years). Preoperatively, the mean ROM of the knee in group A and B were $95.8^{\circ} \pm 18.1^{\circ}$ and $95.4^{\circ} \pm 17.8^{\circ}$, respectively $(p=0.7521)$. The mean varus of deformity in group A and group B were $8.5^{\circ} \pm 2.6^{\circ}$ and $9.8 \pm 3.1^{\circ}$, respectively $(p=0.1498)$. The mean FJS-12 scores of group A and B were $11.90 \pm$ 11.3 and $11.72 \pm 12.1 \quad(p=0.8298)$. The mean hospital stay for patients in group A and B was $4.4 \pm 0.5$ and $4.6 \pm 0.4$ days, respectively (Table 1 ).

Six weeks after TKA, the mean ROM of the knee in group $\mathrm{A}$ and $\mathrm{B}$ was $109.7^{\circ} \pm 22.3^{\circ}$ and $121^{\circ} \pm 21.5^{\circ}$, respectively $(p<0.0001)$. Postoperative hip-knee-ankle angle of the group $\mathrm{A}$ and $\mathrm{B}$ was $181.4^{\circ} \pm 0.5^{\circ}$ and $182.5^{\circ} \pm 0.2^{\circ}$, respectively $(p=0.1302)$. The mean postoperative FJS-12 scores of the group A and B were $24.5 \pm$ 16.4 and $25.6 \pm 17.4$, respectively $(p=0.3625)$. The MUA rates were $3 \%$ in group $\mathrm{A}$ and $0.2 \%$ in group $\mathrm{B}(p=$ 0.0001) (Table 2).

The sample size was estimated to be 870 with a error of $0.05, \beta$ error of 0.1 , and power of 90 . Considering dropouts, it was rounded to 900 patients who had undergone TKA. The MUA rate of group B (0.2\%) was less than that of group A $(3 \%)(p=0.0001)$. The MUA rate of group B was also less than the MUA rates (4 to $6 \%)$ reported in large Western cohorts $(p<0.001 ; 95 \%$ confidence interval - 0.002) (Table 3).

\section{Discussion}

Stiff knee after primary TKA is a very debilitating condition. If left untreated, it will affect patients' daily

Table 2 Comparison of postoperative characteristics of patients between Group A and Group B

\begin{tabular}{|c|c|c|c|}
\hline Parameters & Group A & Group B & $p$ value \\
\hline Mean hospital stay duration (days) & $4.4 \pm 0.5$ & $4.6 \pm 0.4$ & 0.0734 \\
\hline Mean Postoperative VAS score at 6 weeks & $4.5 \pm 1.8$ & $4.3 \pm 1.4$ & 0.0674 \\
\hline Mean Postoperative FJS-12 at 6 weeks & $24.5 \pm 16.4$ & $25.6 \pm 17.4$ & 0.3625 \\
\hline Mean Postoperative Knee Alignment (HKA angle or FT angle) (degrees) & $181.4 \pm 0.5$ & $182.5 \pm 0.2$ & 0.1302 \\
\hline Mean Postoperative ROM & $109.7 \pm 22.3$ & $121.3 \pm 21.5$ & $<0.0001$ \\
\hline MUA Rate & $n=9(3 \%)$ & $n=1(0.1667 \%)$ & 0.0001 \\
\hline
\end{tabular}


Table 3 MUA rate of current study versus the rates of other large cohorts with $p$ values

\begin{tabular}{lllll}
\hline Author & Country of study & Patients $(\boldsymbol{n})$ & MUA rate & $\boldsymbol{p}$ value \\
\hline Werner & USA & 141016 & 4.3 & $<0.001$ \\
Bawa & USA & 3224 & 4.3 & $<0.001$ \\
Issa & USA & 3128 & 4.9 & $<0.001$ \\
Pamilo & Finland & 624 & 5.9 & $<0.001$ \\
Wied & Denmark & 259 & 5.8 & $<0.001$ \\
Current study & India & 600 & 0.167 & \\
\hline
\end{tabular}

activities, such as climbing up and down the stairs, rising from a chair, or tying shoelaces that routinely requires the knee to flex more than $90^{\circ}[17,25-27]$. Asian population even requires more than $120^{\circ}$ to perform certain activities, such as squatting and sitting cross-legged.

We found that physiotherapy at home with physiotherapist visiting decreased the MUA rate, compared with no visiting. Our results were also lower than those of the previous large cohort studies. We believe the constant feedback mechanism between the physiotherapists and patients is helpful in reducing the incidence of stiff knee, thereby decreasing the MUA rate.

Many treatment options are available for managing the stiff knee. Initially, the patients are subjected to aggressive physiotherapy. If the physiotherapy fails to help the patient achieve an acceptable ROM, MUA is indicated. Even though the MUA helps in achieving satisfactory ROM after the procedure, the occurrence of stiff knee should be prevented in the first place. Werner et al. [28] showed that MUA applied within 6 months after TKA increased the risk of early revision of TKA.

Some factors may be associated with the development of stiff knee after TKA. Werner et al. [28] found age < 65 years, female gender, and smoking were associated with a high MUA rate. Issa et al. [29] showed that white race, preoperative diabetes, high cholesterol levels, preoperative $\mathrm{ROM}<100^{\circ}$, and osteonecrosis of the knee were associated with an increased MUA rate.

The study had several limitations. First, this study was not a prospective, blinded, or randomized study. Patient characteristics, such as age, BMI, ROM, varus deformity, knee pain, and FJS-12 may not reflect the actual statistical differences. The cost of both types of physiotherapies was not assessed, which might affect patients' selection of treatments.

\section{Conclusion}

After TKA, frequent physiotherapist's instruction helps the patients improve knee exercises and therefore decrease the risk of revision surgery. The home physiotherapy under supervision of physiotherapist also decreases the MUA rate.

\section{Abbreviations}

TKA: Total Knee Arthroplasty; MUA: Manipulation Under Anaesthesia; ROM: Range of Motion; VAS: Visual Analogue Score; FJS-12: Forgotten Joint Score-12

\section{Acknowledgements \\ We acknowledge the help provided by Mr. Vishal Jagadale, a statistician.}

\section{Authors' contributions}

All authors have contributed significantly to the preparation of manuscript.

The authors read and approved the final manuscript.

Funding

No funding was obtained.

\section{Availability of data and materials \\ Not Applicable.}

Ethics approval and consent to participate

Local ethics committee approval was obtained before the study. Also all patients gave their consent.

Consent for publication

We hereby give our consent for publication.

\section{Competing interests}

The authors declare that they have no competing interests.

\section{Author details}

${ }^{1}$ Orthopaedic surgeon, Criticare Hospital, Plot No 516, Besides SBI, Teli Gali, Andheri East, Mumbai, Maharashtra 400069, India. ${ }^{2}$ Orthopaedic Surgeon, Hinduja Healthcare, Khar, India. ${ }^{3}$ Meril Life Sciences, Mumbai, India. ${ }^{4}$ Dr Vishwanath Karad MIT World Peace University, Pune, India. ${ }^{5}$ Criticare Hospital, Mumbai, India. ${ }^{6}$ Alpha speciality Clinic, Mumbai, India. ${ }^{7}$ SDM College of Physiotherapy, Sattur, Dharwad, Karnataka, India.

Received: 30 April 2020 Accepted: 14 December 2020

Published online: 03 March 2021

\section{References}

1. Riley LH Jr. Total knee arthroplasty. Clin Orthop Relat Res. 1985;192:34-9.

2. Genêt F, Schnitzler A, Lapeyre E, et al. Change of impairment, disability and patient satisfaction after total knee arthroplasty in secondary care practice. Ann Readapt Med Phys. 2008;51:671-6 676-82. English, French.

3. Mainard D, Guillemin F, Cuny C, et al. Quality of life assessment one year after total hip or knee arthroplasty. Rev Chir Orthop Reparatrice Appar Mot. 2000;86:464-73 French.

4. Heck DA, Robinson RL, Partridge CM, Lubitz RM, Freund DA. Patient outcomes after knee replacement. Clin Orthop Relat Res. 1998;356:93-110.

5. Beswick AD, Wylde V, Gooberman-Hill R, Blom A, Dieppe P. What proportion of patients report long-term pain after total hip or knee replacement for osteoarthritis? A systematic review of prospective studies in unselected patients. BMJ Open. 2012;2:e000435.

6. Kane RL, Saleh KJ, Wilt TJ, Bershadsky B. The functional outcomes of total knee arthroplasty. J Bone Joint Surg Am. 2005;87:1719-24.

7. Bourne RB, Chesworth BM, Davis AM, Mahomed NN, Charron KD. Patient satisfaction after total knee arthroplasty: who is satisfied and who is not? Clin Orthop Relat Res. 2010;468:57-63.

8. Anderson JG, Wixson RL, Tsai D, Stulberg SD, Chang RW. Functional outcome and patient satisfaction in total knee patients over the age of 75 . J Arthroplast. 1996;11:831-40.

9. Chesworth BM, Mahomed NN, Bourne RB, Davis AM. Willingness to go through surgery again validated the WOMAC clinically important difference from THR/TKR surgery. J Clin Epidemiol. 2008:61:907-18.

10. Dunbar MJ, Robertsson O, Ryd L, Lidgren L. Appropriate questionnaires for knee arthroplasty, results of a survey of 360patients from the Swedish knee Arthroplasty registry. J Bone Joint Surg Br. 2001;83:339-44.

11. Hawker G, Wright J, Coyte P, Paul J, Dittus R, Croxford R, Katz B, Bombardier C, Heck D, Freund D. Health-related quality of life after knee replacement. Results of the knee replacement patient outcomes research team study. J Bone Joint Surg Am. 1998;80:163-73. 
12. Noble PC, Conditt MA, Cook KF, Mathis KB. The John Insall award: patient expectations affect satisfaction with total knee arthroplasty. Clin Orthop Relat Res. 2006;452:35-43.

13. Robertsson O, Dunbar M, Pehrsson T, Knutson K, Lidgren L. Patient satisfaction after knee arthroplasty: a report on 27,372knees operated on between 1981 and 1995 in Sweden. Acta Orthop Scand. 2000;71:262-7.

14. Carr AJ, Robertsson O, Graves S, Price AJ, Arden NK, Judge A, Beard DJ. Knee replacement. Lancet. 2012;379:1331-40.

15. Bong MR, Di Cesare PE. Stiffness after total knee arthroplasty. J Am Acad Orthop Surg. 2004;12:164-71.

16. Kettelkamp DB, Leaverton PE, Misol S. Gait characteristics of the rheumatoid knee. Arch Surg. 1972;104:30-4.

17. Laubenthal KN, Smidt GL, Kettelkamp DB. A quantitative analysis of knee motion during activities of daily living. Phys Ther. 1972;52:34-43.

18. Kim J, Nelson CL, Lotke PA. Stiffness after total knee arthroplasty. Prevalence of the complication and outcomes of revision. J Bone Joint Surg Am. 2004; 86:1479-84.

19. Parvizi J, Nunley RM, Berend KR, Lombardi AV Jr, Ruh EL, Clohisy JC, Hamilton WG, Della Valle CJ, Barrack RL. High level of residual symptoms in young patients after total knee arthroplasty. Clin Orthop Relat Res. 2014;472: 133-7.

20. Pivec R, Issa K, Kester M, Harwin SF, Mont MA. Long-term outcomes of MUA for stiffness in primary TKA. J Knee Surg. 2013;26:405-10.

21. Parvizi J, Tarity TD, Steinbeck MJ, Politi RG, Joshi A, Purtill JJ, Sharkey PF. Management of stiffness following total knee arthroplasty. J Bone Joint Surg Am. 2006:88(Suppl 4):175-81.

22. Ries MD, Badalamente M. Arthrofibrosis after total knee arthroplasty. Clin Orthop Relat Res. 2000;380:177-83.

23. Ritter MA, Stringer EA. Predictive range of motion after total knee replacement. Clin Orthop Relat Res. 1979;143:115-9.

24. Robertson F, Geddes J, Ridley D, McLeod G, Cheng K. Patients with type 2 diabetes mellitus have a worse functional outcome post knee arthroplasty: a matched cohort study. Knee. 2012:19:286-9.

25. Seyler TM, Marker DR, Bhave A, Plate JF, Marulanda GA, Bonutti PM, Delanois RE, Mont MA. Functional problems and arthrofibrosis following total knee arthroplasty. J Bone Joint Surg Am. 2007;89(Suppl 3):59-69.

26. Vince KG. The stiff total knee arthroplasty: causes and cures. J Bone Joint Surg Br. 2012;94:103-11.

27. Nelson CL, Kim J, Lotke PA. Stiffness after total knee arthroplasty. J Bone Joint Surg Am. 2005;87(Suppl 1):264-70.

28. Werner BC, Carr JB, Wiggins JC, Gwathmey FW, Browne JA. Manipulation under anesthesia after total knee arthroplasty is associated with an increased incidence of subsequent revision surgery. J Arthroplast. 2015;30(9 Suppl):72-5

29. Issa K, Rifai A, Boylan MR, Pourtaheri S, McInerney VK, Mont MA. Do various factors affect the frequency of manipulation under anesthesia after primary total knee arthroplasty? Clin Orthop Relat Res. 2015;473(1):143-7.

\section{Publisher's Note}

Springer Nature remains neutral with regard to jurisdictional claims in published maps and institutional affiliations.

Ready to submit your research? Choose BMC and benefit from:

- fast, convenient online submission

- thorough peer review by experienced researchers in your field

- rapid publication on acceptance

- support for research data, including large and complex data types

- gold Open Access which fosters wider collaboration and increased citations

- maximum visibility for your research: over $100 \mathrm{M}$ website views per year

At $\mathrm{BMC}$, research is always in progress.

Learn more biomedcentral.com/submissions 